\title{
DUCHENNE MUSCULAR DYSTROPHY - FAMILY IN A CRISIS
}

\author{
M ROBED AMIN ${ }^{1}$, CHOWDHURY CHIRONJIB BORUA ${ }^{2}$, KAJI SHAFIQUL ALAM ${ }^{3}$, FAZLE RABBI \\ $\mathrm{CHOWDHURY}^{4}$, RABIUL JAHAN SARKAR $^{5}$, MD. ABUL KASHEM KHANDAKER ${ }^{6}$, MA FAIZ ${ }^{7}$
}

\section{Introduction:}

Progressive muscular weakness with deformity leading to crippled states develop due to musculoskeletal and neurological disorders. Sometimes it is difficult to differentiate between primary muscle disease and neurological disease. But there is some classical presentation of muscle diseases which have its own entity and thus can be clinically differentiated from neurological disorder especially spinal cord and motor neuron diseases. Muscular dystrophy is one of those disorder with distinct clinical features. Muscular dystrophy refers to a group of genetic, hereditary muscle diseases that cause progressive muscle weakness. ${ }^{1,2}$ Most types of $\mathrm{MD}$ are multi-system disorders with manifestations in body systems including skeletal system, the heart, gastrointestinal and nervous systems, endocrine glands, skin, eyes and other organs. ${ }^{3,4}$ Duchenne muscular dystrophy (DMD) ${ }^{5}$, is inherited in an Xlinked recessive pattern, meaning that the mutated gene that causes the disorder is located on the $\mathrm{X}$ chromosome, one of the two sex chromosomes, and is thus considered sex-linked. Males are therefore affected by X-linked recessive disorders much more often than females. A characteristic of X-linked inheritance is that fathers cannot pass X-linked traits to their sons. Duchenne muscular dystrophy and Backers muscular dystrophy are caused by mutations of the gene for the dystrophin protein and lead to an overabundance of the enzyme creatine kinase. ${ }^{6,7}$ The dystrophin gene is the largest gene in humans. ${ }^{8}$ In this case series a family with three brothers suffering from Duchenne muscular dystrophy is described and review with literature was done.

\section{Case Summary:}

$\mathrm{X}$ (17 yrs), Y ( $14 \mathrm{yrs})$ and Z (11 yrs)- 3 brothers; sons of Mr. N, 55 yrs day- labor with poor socioeconomic status having permanent residence Alipur, Hathazari and presented in Hathazari Health Complex on 29.8.08 with the complaints of progressive muscular weakness and wasting of all 4 limbs, which initiated from lower limbs and then gradually involve the upper limbs. The weakness started with proximal weakness bilaterally especially from sitting to standing position and during toilet activities. The Muscle weakness occurred in pelvis and calf muscles followed by arms, neck, and other areas.Gradually weakness increases in all three brothers with development of contracture of lower limbs and flabbiness in upper limbs leading to crippled situation. The weakness started at around 8 to 9 years of age in all three brothers and progress to crippled stage within 3 to 4 years. The physical symptoms are awkward gait (In Z- patient tend to walk on his forefeet, because of an increased calves tonus. X and Y Are bed bound). There is history of frequent falls during walking in all three brothers associated with fatigue. They developed difficulty with motor skills like running, hopping, jumping gradually and it was followed by increased Lumbar lordosis, leading to shortening of the hip-flexor muscles. This has an affect on overall posture and gait. Muscle contractures of achilles tendon and hamstrings ensued with progressive difficulty in walking. Psedohypertrophy of calf muscles where enlarged muscle tissue is eventually replaced by fat and connective tissue were very prominent in these patients. They also have behavior and learning difficulties. The three brothers at last have lost of

1. Assistant Professor, Department of Medicine, Dhaka Medical College

2. Consultant (Pediatrics), Anowara Health Complex, Chittagong

3. Thana Health and Family Planning Officer, Hathazari Health Complex, Chittagong

4. Medical Officer Disease Control, Hathazari Health Complex, Chittagong

5. Surveillance Medical Officer, WHO

6. Professor and Head of Department of Medicine, Dhaka Medical College

7. Director General of Health Service and Professor of Medicine, DGHS, Dhaka

Correspondence : Dr. M Robed Amin, Assistant Professor, Department of Medicine, Dhaka Medical College 
ability to walk ( by the age of $11-12$ years in $\mathrm{X}$ and $\mathrm{Y}$ and 10 years in $Z$ ) associated with Skeletal deformities ( scoliosis in $\mathrm{X}$ and $\mathrm{Y}$ ).

There is strong family history of similar weakness in maternal side with three of the cousins are also involved.

There was no history of fever or diarrhoea or respiratory symptoms before or during the development of weakness. The mother mentioned that the children were immunized in the routine immunization program and all 3 children have taken OPV several times during National Immunisation Programme (NID). But the mother could not produce any document or vaccination card.

There is no history of headache or any ENT related symptoms or any systemic symptomatology on enquiry. There is no history of prolonged drug, alcohol or toxin exposure.

The family tree of this poor family reveals affected three brothers and three affected cousins. Beside the 7 children, 2 children of the family have died; one of the death was due to Neonatal Asphyxia and the other at 3 months due to Pneumonia. (Pedigree tree attached below) (Table-I).
General examination revealed no abnormality except puffy face with pallor. Their pulse were found 140/ min, 124/ min and 108/ min respectively in X, Y and Z Musculo-skeletal and Neurological examination revealed that Gross weakness of all 4 limbs of $X$ and $\mathrm{Y}$ (grade 1) and mild wasting of Z. Wasting presented predominantly in deltoid, supra-spinatus, trapezius and also pelvic girdle including gluteus and thigh muscles (Fig.-1).There is contracture around knee and ankle joints in $\mathrm{X}$ and $\mathrm{Y}$ were seen. All reflexes are grossly diminished in $\mathrm{X}$ and $\mathrm{Y}$ and mild diminish in Z. Hypertrophy of calf muscles of all brothers associated with flabbiness in upper limbs with sleeping sign ('slip through the hands' on being lifted, due to hypotonia of muscles around the shoulder.) were observed in all three cases (Fig.-2). There was history of Gower Sign (on enquiry) (Climbing up legs' using the hands when rising from the floor) with no sensory deficit.

No cerebellar or cranial nerve lesion was seen and no gross abnormality in higher central function except low IQ was observed.

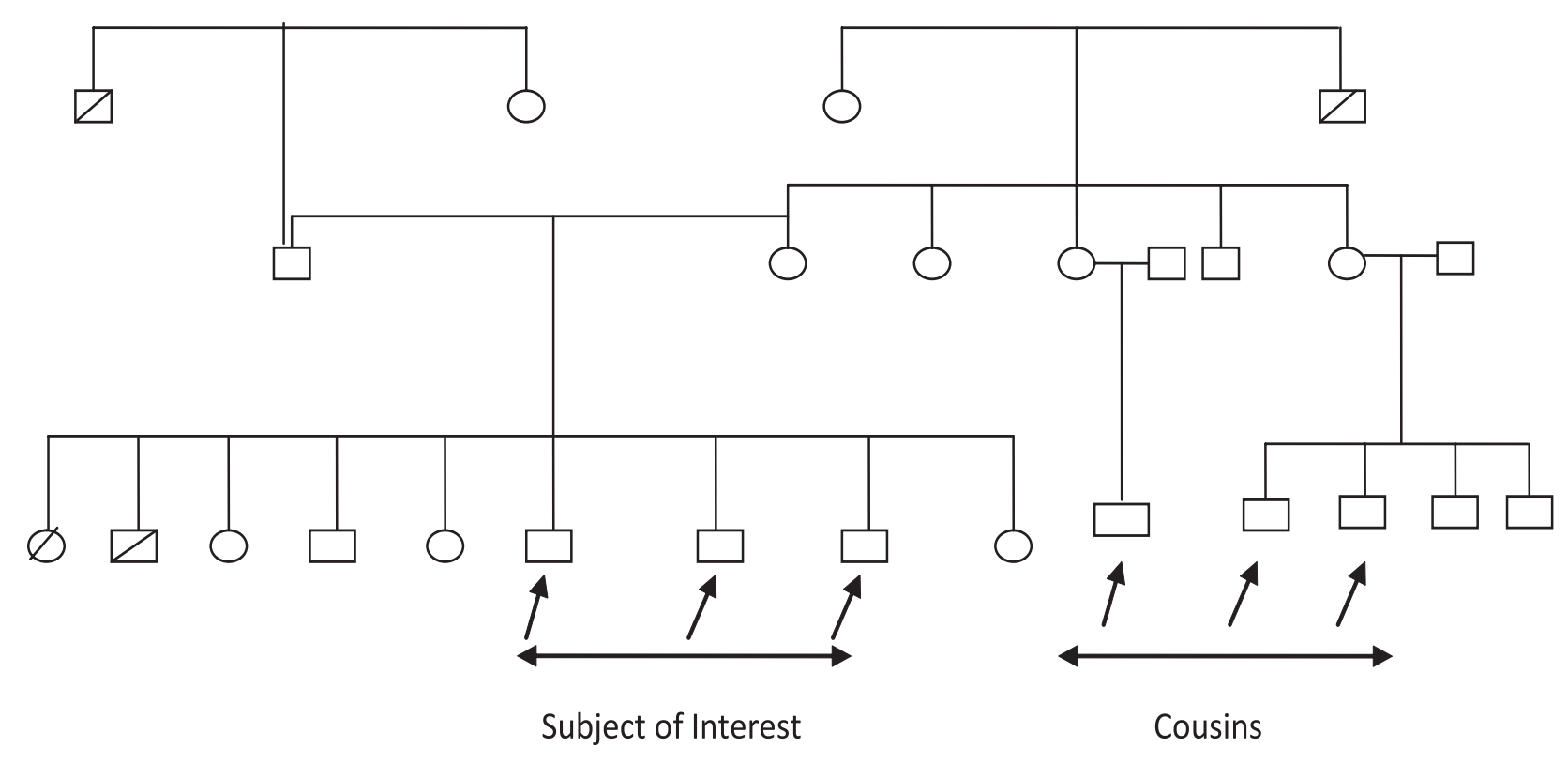

Table-I: Family tree (pedigree) revealed the disorder of $X$ linked recessive trait 


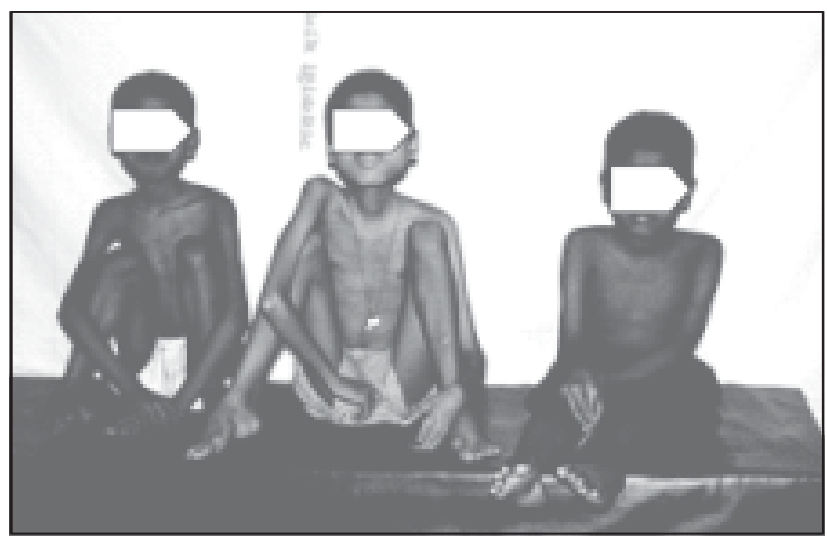

Fig 1: Three brothers with muscle weakness and wasting.

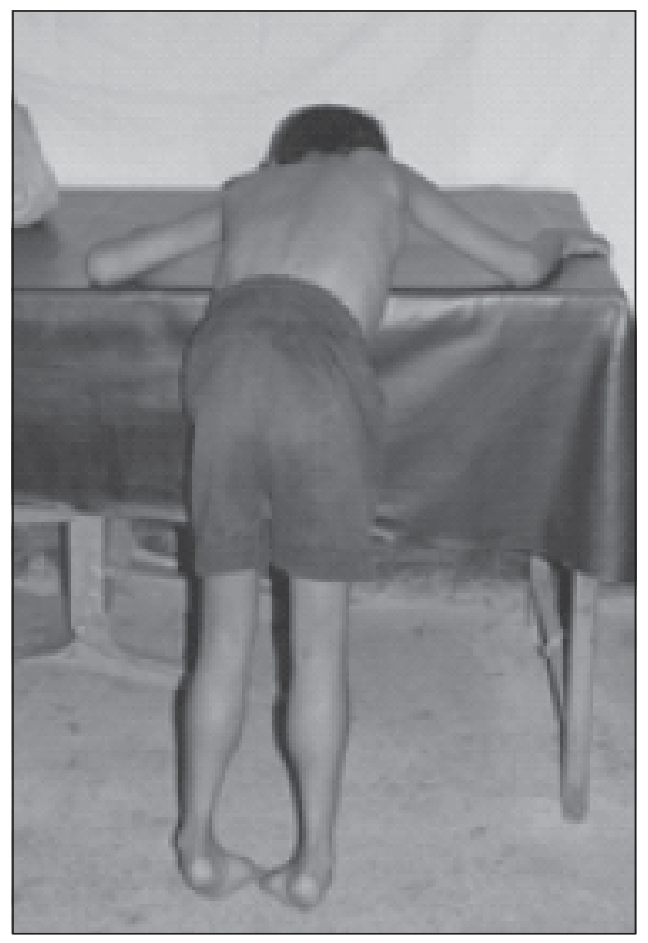

Fig 2: Pseudohypertrophy of calf muscles

Systemic enquiry including locomotor and cardiovascular system revealed no abnormality. Genito-urinary system evaluation revealed no testicular atrophy. There is no baldness, facial deformity or cataract was observed. Clinically three brothers were diagnosed as Hereditary Myopathy (Duchenne Muscular Dystrophy).

Discusssion: Family pedigree, inheritance, symptoms in three brothers and clinical signs all revealed the diagnosis of Duchenne Muscular Dystrophy in this case series. Symptoms of DMD usually appear in male children before age 6 and may be visible in early infancy. Progressive proximal muscle weakness of the legs and pelvis associated with a loss of muscle mass is observed first. Eventually this weakness spreads to the arms, neck, and other areas ${ }^{9}$. In these three brothers the symptoms started after age 8 yrs which is not consistent with other text book. It could be due to lack of observation in parents as they had to take care of many children and poverty. The trivial difficulty in walking, jumping, hooping in playground and school could have been started before parents notice of gower sign and toilet activity. Early signs may include pseudohypertrophy (enlargement of calf muscles), low endurance, and difficulties in standing unaided or inability to ascend staircases. As the condition progresses, muscle tissue experiences wasting and is eventually replaced by fat and fibrotic tissue (fibrosis) ${ }^{10}$. This is consistent with the case series as all three brothers had gross hypertrophy of calf muscles. The $\mathrm{X}$ and $\mathrm{Y}$ are having gross generalized wasting except calf muscle while $\mathrm{Z}$ although had mild generalized wasting still have very prominent calves. By age 10, braces may be required to aid in walking but most patients are wheelchair dependent by age $12^{1,4}$. This is very much consistent in three brothers' especially in $\mathrm{X}$ and $\mathrm{Y}$ who are actually bed ridden with painful contractures due to lack of physiotherapy and orthotics. Later symptoms of DMD may include abnormal bone development that lead to skeletal deformities, including curvature of the spine. Due to progressive deterioration of muscle, loss of movement occurs eventually leading to paralysis ${ }^{4,9}$. In this case series $\mathrm{X}$ and $\mathrm{Y}$ are already in paralytic stage while the $\mathrm{Z}$ is just able to stand and sit with no muscular activity.

Complications of DMD are: Joint contracture, respiratory muscle failure leading to hypoventilation, loss of coughing and respiratory infections, cardiomyopathy ,cardiac arrhythmias. About $20 \%$ of DMD patients have learning difficulty.Respiratory failure, pneumonia and/or cardiomyopathy are the usual cause of death ${ }^{11}$. The two brothers in this case series had joint contracture ( $\mathrm{X}$ and $\mathrm{Y}$ ). Although all three of them had sinus tachycardia, there was no cardiomegaly or any sign in chest. The average life expectancy for patients afflicted with DMD varies from early teens to age mid 30s. In our series three brothers have low IQ and it seems their prognosis will going to be worst in near future. 
Cratine kinase(CPK-MM) levels in the bloodstream are usually extremely high inaffected individuals and can reach as high as 15,000 to 35,000iu/l (normal $=$ $60 \mathrm{iu} / \mathrm{l})$. An electromyography (EMG) may shows weakness is caused by destruction of muscle tissue rather than by damage to nerves. Genetic testing can reveal genetic errors in the Xp21 gene. A muscle biopsy (immunohistochemistry or immunoblotting) or genetic test (blood test) confirms the absence of dystrophin, although improvements in genetic testing often make this unnecessary.

Chorion villus sampling (CVS) at 10-12 weeks, and amniocentesis at about 14-16 weeks would allow early termination which would probably be less traumatic for the couple, but it carries a slightly higher risk of miscarriage than later testing ${ }^{12}$. In this case study we could not do any investigation as they are the very poor and not interested to go for tertiary care.

There is no known cure for Duchenne muscular dystrophy, although recent stem-cell research is showing promising vectors that may replace damaged muscle tissue. Treatment is generally aimed at control of symptoms to maximize the quality of life, and include the following.

1. Corticosteroids such as prednisone and deflazacort increase energy and strength and defer severity of some symptoms.

2. Mild, non-jarring physical activity such as swimming is encouraged. Inactivity (such as bed rest) can worsen the muscle disease.

3. Physical therapy is helpful to maintain muscle strength, flexibility, and function.

4. Orthopedic appliances (such as braces and wheelchairs) may improve mobility and the ability for self-care. Form-fitting removable leg braces that hold the ankle in place during sleep can defer the onset of contractures.

5. Appropriate respiratory support as the disease progresses is important

Promising research is being conducted to find gene therapy. These thzerapies include: stem cell replacement, exon-skipping, analog utropin upregulation, and gene replacement. A few Clinical Trials like PTC124 and 2'-O-methyl phosphorothioate oligos are in progress ${ }^{13,14}$.

\section{Conclusion:}

The Duchenne Muscular Dystrophy is a serious hereditary myopathy that is universally fatal in growing age.The complication and suffering are beyond limit of tolerance. The genetic counseling is vital for prevention of this disease. Appropriate counseling and prenatal diagnosis could have save the disaster in this poor family.

\section{References:}

1. Harrison's Principle's of Internal Medicine. 2005; 2527.

2. Louise V. B. Anderson; Katharine M. D. Bushby (2001). Muscular Dystrophy: Methods and Protocols (Methods in Molecular Medicine). Totowa, NJ: Humana Press, 111.

3. Emery AE. The muscular dystrophies. Lancet 2002; 359 (9307): 687-695.

4. Bushby K. Muscular dystrophy. In: Oxford Textbook of Medicine Online, accessed December 2007; In: http://www.doctors.net.uk/

5. Aran FA. Recherches sur une maladie non encore décrite du système musculaire (atrophie musculaire progréssive).Archives générales de médecine, Paris, 1850; 24: 172-214.

6. Chakkalakal JV, Thompson J, Parks RJ, et al. Molecular, cellular, and pharmacological therapies for Duchenne/Becker muscular dystrophies. FASEB J 2005; 19(8): 880-91.

7. Prior TW, Bridgeman SJ. Experience and strategy for the molecular testing of Duchenne muscular dystrophy. J Mol Diagn 2005;7(3):317-26.

8. Tennyson, $\mathrm{C}$ et al. "The human dystrophin gene requires 16 hours to be transcribed and is cotranscriptionally spliced." Nature Genetics 1995; 9: $184-190$.

9. Grain L, Cortina-Borja M, Forfar C, et al. Cardiac abnormalities and skeletal muscle weakness in carriers of Duchenne and Becker muscular dystrophies and controls. Neuromuscul Disord 2001; 11(2): 186-91.

10. Essex C, Roper H. Lesson of the week: late diagnosis of Duchenne's muscular dystrophy presenting as global developmental delay. BMJ 2001; 323(7303): 37-8.

11. Holloway SM, Wilcox DE, Wilcox A, et al. Life expectancy and death from cardiomyopathy amongst carriers of Duchenne and Becker muscular dystrophy in Scotland. Heart 2007: 11.

12. Prior TW, Bridgeman SJ; Experience and strategy for the molecular testing of Duchenne muscular dystrophy. J Mol Diagn 2005;7(3):317-26.

13. Clinical Trails.gov NCT00159250 Safety and Efficacy Study of Antisense Oligonucleotides in Duchenne Muscular Dystrophy for exon skipping with Morpholino oligos

14. Clinical Trial gov Information for 2'-O-methyl phosphorothioate (PRO051) trial. 